\title{
THERMO-OPTICAL AND WOUND HEALING PROPERTIES OF CERTAIN NEW POLY(ESTER AMIDES)
}

\author{
V. Chitra and D. Roopsingh* \\ PG \& Research Department of Chemistry, Presidency College, Chennai-600 005, \\ Tamilnadu, India \\ *E-mail: roopsinghd@gmail.com
}

\begin{abstract}
A series of six new poly(ester amides) (PEAs) are synthesized from 2,5-pyridine dicarboxylic acid and structurally different diamines and diols by direct polycondensation. The three diols employed are 1,8-dihydroxyanthraquinone, hydroquinone bis(2-hydroxyethyl)ether and hydroquinone. Two diamines, namely 1,6-diamino hexane and 1,4diamino benzene are used in polymerization. These polymers are characterized extensively by spectroscopic techniques such as as ${ }^{1} \mathrm{HNMR},{ }^{13} \mathrm{C}$ NMR and FTIR spectra. The different properties of this poly (ester amides) such as inherent viscosity and qualitative solubility are reported. The thermal characteristics of the poly(ester amides) are determined by differential scanning calorimetry (DSC). The liquid crystalline behavior of the polymers is identified by optical polarizing microscopy (OPM). The degree of crystallinity of the PEAs is studied by wide-angle X-ray diffraction (WAXD) method. Typical polymers are also tested for in vitro wound scratch assay.

Keywords: Poly(ester amides), 2,5-Pyridinedicarboxylic Acid, Direct Polycondensation, Characterization; LC Properties, Wound Scratch Assay.
\end{abstract}

(C) RASĀYAN. All rights reserved

\section{INTRODUCTION}

In the last decade, there are several reports on the synthesis and characterization of poly(ester amides) (PEAs) having different chain microstructures. To evaluate the influence of microstructure on the properties of PEAs, considerable efforts have currently been devoted. ${ }^{1,2}$ As PEAs possess amide and ester groups in the polymer they form strong intermolecular hydrogen bonding that enhances the mechanical and thermal properties to the polymeric materials. ${ }^{3-5}$ PEAs are considered as materials having potential to exhibit thermal, mechanical, biological and optical properties for a wide range of application in various fields ${ }^{6-8}$. The influence of several aromatic moieties that differ in size and structure on the intermolecular interactions of PEAs and their liquid crystalline behavior were studied by Sudha and Pillai. ${ }^{9}$ The effects of chemical structure of PEAs on the thermal, mechanical and optical properties were studied. ${ }^{10}$ Priya Garg et al. reported that the thermal properties of the three different series of segmented PEAs are dependent on the microstructure of the polymers. ${ }^{11} \mathrm{~A}$ wide variety of biodegradable PEAs can be produced by blending them with suitable renewable resources like carbohydrates and amino acids that can offer biocompatibility. By varying the composition of synthetic blend component, the morphology and hence the other properties can be regulated easily and efficiently. ${ }^{12-14}$ Properties of polymers are dependent on the great variety of monomers used. The selection of monomers plays a vital role in the design and development of biomedical products. ${ }^{15-17}$ There are a variety of methods available for the synthesis of polymers. ${ }^{18,19}$ The most convenient and less time-consuming method is direct polycondensation which bypasses the tedious step of diacid chloride formation. We report here studies on the preparation and characterization of a new series of PEAs based on 2,5-pyridine dicarboxylic acid linked to various diols and diamines using diphenyl phosphoryl chloride (DPPC) as the agent for polycondensation in pyridine solvent. To study the effect of thermal stability and optical property, monomers of different molecular structures are used. Moreover the wound healing capacity of the

Rasayan J. Chem., 12(4), 2124-2131(2019)

http://dx.doi.org/10.31788/RJC.2019.1245431

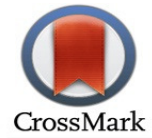


synthesized PEAs was also investigated. Since these PEAs were reported to possess antimicrobial activity by earlier workers. ${ }^{20}$

\section{Material and Methods}

\section{EXPERIMENTAL}

2,5-Pyridinedicarboxylic acid, 1,8-dihydroxyanthraquinone, hydroquinone bis(2-hydroxy ethyl)ether, hydroquinone, 1,6-diamino hexane, 1,4-diamino benzene, diphenyl phosphoryl chloride (99\%) and anhydrous lithium chloride (99\%) were obtained from Aldrich. Pyridine (Merck) used as a solvent for polymerization was refluxed over potassium hydroxide pellets, distilled (B.P. $115^{\circ} \mathrm{C}$ ) and kept in ambercolored bottles. Tetrahydrofuran and methanol (Merck, India) were distilled (B.P. $65^{\circ} \mathrm{C}$ ) before use. For NMR spectral analysis Aldrich sample of DMSO- $\mathrm{d}_{6}$ with TMS as internal standard was used.

\section{Synthetic Procedure for Poly (Ester Amides)}

The procedure for the synthesis of poly(ester amide) PDAB by direct polycondensation is as follows: ${ }^{21}$ A mixture of $5 \mathrm{mmol}(0.835 \mathrm{~g})$ of 2,5-pyridine dicarboxylic acid, $13 \mathrm{mmol}(2.694 \mathrm{ml})$ of DPPC and pyridine were added in a three-necked $250 \mathrm{ml}$ round-bottom flask fitted with a thermometer, condenser, mechanical stirrer $(350 \mathrm{rpm} / \mathrm{min})$ and an oil bath. After $20 \mathrm{~min}$. of stirring $10 \mathrm{mmol}(0.4250 \mathrm{~g})$ of $\mathrm{LiCl}$ in pyridine was added and the reaction mixture was slowly heated up to $120{ }^{\circ} \mathrm{C}$. To this mixture $2.5 \mathrm{mmol}$ $(0.6 \mathrm{~g})$ of 1,8-dihydroxyanthraquinone and $2.5 \mathrm{mmol}(0.27 \mathrm{~g})$ of 1,4-diamino benzene in pyridine was added. The whole solution was stirred at $120{ }^{\circ} \mathrm{C}$ for 3 hours, then cooled and poured into $500 \mathrm{ml}$ water/methanol mixture. The precipitate was filtered, washed thoroughly with hot methanol and dried.

\section{Characterization of Poly(Ester Amides)}

The inherent viscosity $\left(\eta_{\text {inh }}\right)$ values of poly(ester amides) were determined at a concentration of $0.1 \mathrm{~g} \mathrm{dL}$ 1in N, N-dimethylacetamide using an Ubbelohde viscometer. The solubility of the polymers was qualitatively determined using $0.01 \mathrm{~g}$ of the PEA in $2 \mathrm{~mL}$ of the solvent. The infrared spectra of the polymer samples were recorded by Bruker $\alpha$-T FT-IR spectrophotometer using a $\mathrm{KBr}$ pellet from $500 \mathrm{~cm}-$ 1 to $4500 \mathrm{~cm}-1$. The ${ }^{1} \mathrm{H}$ NMR and ${ }^{13} \mathrm{C}$ NMR spectra were recorded by a Bruker-500MHz spectrometer using DMSO- $\mathrm{d}_{6}$ solvent. DSC thermograms were recorded at a scan rate of $10^{\circ} \mathrm{C} / \mathrm{min}$ on the Netzsch phoenix DSC 204 instrument under a nitrogen atmosphere. The degree of crystallinity of the PEAs was studied at room temperature using the PANalytical - X Pert Pro X-ray diffractometer.

\section{Scratch Wound Healing Assay (In vitro)}

Vero cells were seeded onto 6-well plate at a density of $2 \times 10^{5}$ cells and incubated overnight at $37^{\circ} \mathrm{C}$ and $5 \% \mathrm{CO}_{2}$. Cell culture monolayers were scratched horizontally with a sterile pipette tip. Thereafter, the cells were treated with polymer at two different concentrations ( 25 and $12.5 \mu \mathrm{g}$ ) by diluting with growth medium. The cell without treatment was used as the control. After 24 hours treatment period, the plates were viewed under a microscope. To calculate the wound closure, the images were observed and the percentage of migration rate was calculated by using the following formula: ${ }^{22}$

Migration Rate $(\%)=[($ Measurement at $0 \mathrm{~h}-$ Measurement at $24 \mathrm{~h}) /$ Measurement at $0 \mathrm{~h}] \times 100$

Table-1: Polymer Code, Monomers Used, \% Yield, Inherent Viscosity and Absorption Frequencies in FTIR Spectra of PEAs

\begin{tabular}{c|c|c|c|c|c|c|c|c}
\hline PEA Code & $\begin{array}{c}\text { Monomers } \\
\text { Mole ratio } \\
2: 1: 1)\end{array}$ & Colors & Yield (\%) & $\eta_{\text {inh }}$ & \multicolumn{4}{|c}{ FTIR Data $\left(\mathrm{cm}^{-1}\right)$} \\
\cline { 6 - 9 } & & & & & $\mathrm{C}=\mathrm{O}$ & $\mathrm{C}=\mathrm{C}$ & $\mathrm{C}-\mathrm{O}-\mathrm{C}$ & CO-NH \\
\hline PDAH & PD+DA+DH & Yellow & 85 & 1.27 & 1744 & 1463 & 1263 & 2924 \\
\hline PDAB & PD+DA+DB & Green & 88 & 1.15 & 1744 & 1515 & 1272 & 2924 \\
\hline PDEH & PD+HE+DH & Black & 70 & 1.25 & 1723 & 1533 & 1282 & 2937 \\
\hline PDEB & PD+HE+DB & Brown & 75 & 1.18 & 1717 & 1505 & 1229 & 2944 \\
\hline PDHH & PD+HQ+DH & Brown & 80 & 1.20 & 1738 & 1504 & 1265 & 2929 \\
\hline PDHB & PD+HQ+DB & Black & 82 & 1.09 & 1739 & 1513 & 1261 & 2929 \\
\hline
\end{tabular}


Where,

PD- 2,5-pyridinedicarboxylic acid;

DA- 1,8- dihydroxyanthraquinone;

HE- hydroquinone bis(2-hydroxyethyl)ether;

HQ- hydroquinone;

DH- 1,6-diamino hexane;

DB- 1,4-diamino benzene.

\section{RESULTS AND DISCUSSION}

Six PEAs are prepared in the present work. Polymer code, monomers used, \% yield, inherent viscosity and absorption frequencies in FTIR spectra of PEAs are summarized in Table-1.

\section{Solubility of PEAs}

Table -2 contains qualitative solubility data of all the PEAs synthesized. It is found that 2,5-pyridine dicarboxylic acid-based PEAs were soluble in highly polar solvents such as N, N-dimethylformamide (DMF), N, N-dimethylacetamide (DMAc), dimethyl sulphoxide (DMSO) and tetrahydrofuran (THF). They were partially soluble in acetone, chloroform and sparingly soluble in methanol, benzene and hexane.

Table-2: Solubility data of PEAs

\begin{tabular}{|c|c|c|c|c|c|c|c|c|c|}
\hline$\frac{\bar{\Xi}}{\stackrel{\Xi}{0}}$ & 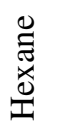 & $\begin{array}{l}\text { D̃ } \\
\text { N } \\
\text { D. } \\
\text { ص. }\end{array}$ & $\underset{\circlearrowright}{\circlearrowright}$ & 岌 & \begin{tabular}{l}
$\stackrel{0}{0}$ \\
$\stackrel{0}{0}$ \\
\multirow{U}{*}{}
\end{tabular} & 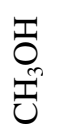 & 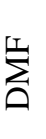 & $\sum_{0}^{0}$ & 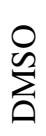 \\
\hline PDAH & - & - & +- & + & +- & - & + & + & + \\
\hline PDAB & - & - & +- & + & +- & - & + & + & + \\
\hline PDEH & - & - & +- & + & +- & - & + & + & +- \\
\hline PDEB & - & - & +- & + & +- & - & + & + & +- \\
\hline $\mathrm{PDHH}$ & - & - & +- & + & +- & - & + & + & +- \\
\hline PDHB & - & - & +- & + & +- & - & + & + & +- \\
\hline
\end{tabular}

+- = partially soluble; - = sparingly soluble; + =highly soluble;

\section{Spectral Analysis}

The microstructures of all the PEAs were investigated by FTIR analysis. Figure-1 displays the representative FTIR spectra of polymer PDAB which show characteristic absorption for carbonyl group of ester at $1744 \mathrm{~cm}^{-1}, \mathrm{C}-0-\mathrm{C}$ (str) at $1272 \mathrm{~cm}^{-1}, \mathrm{C}-\mathrm{O}$ (str) of ester group at $1090 \mathrm{~cm}^{-1}$ and C-H (str) at 2924 $\mathrm{cm}^{-1}$ (asymmetrical). All the PEAs synthesized containing 2,5-pyridine dicarboxylate units exhibit two vibrations at $1515 \mathrm{~cm}^{-1}$ and $1626 \mathrm{~cm}^{-1}$ for $\mathrm{C}=\mathrm{C}$ and $\mathrm{C}-\mathrm{NH}$ vibrations of the pyridine ring. ${ }^{23,24}$ The other five PEAs showed similar FTIR spectra.

The chemical repeat unit in the PEAs was spectrally analyzed by ${ }^{1} \mathrm{H}$ and ${ }^{13} \mathrm{C}$ NMR spectra. The representative ${ }^{1} \mathrm{H}$ NMR spectrum of PEAs

PDAB in DMSO- $\mathrm{d}_{6}$ is presented in Fig. 2. The peak assigned to the portions of the secondary amide group showed in the region of $\delta=10.7 \mathrm{ppm}$. The aromatic protons showed signals in the range of $\delta=7.0$ $7.9 \mathrm{ppm}$. The sharp peak for the protons of diamino hexane moiety showed signals at $\delta=2.0 \mathrm{ppm}$. This data indicates that the polymer backbone contains all three monomers.

A typical ${ }^{13}$ CNMR spectrum of PDAB is presented in Fig.-3. The presence of ester carbonyls in the polymer chain as indicated by signals at $161 \mathrm{ppm}$. The carbonyl group of anthraquinone was indicated by the signals at $192 \mathrm{ppm}$ as these are more deshielded. The carbons of the aromatic ring are shown by the peaks in the range of 116-137 ppm. The peak at $181 \mathrm{ppm}$ represented the presence of amide carbonyl carbon atoms. ${ }^{25}$ The signals assigned indicated that the polymer backbone contains all the three monomers. 
RASĀYAN J. Chem.

Vol. 12 | No. 4 |2124 - 2131| October - December | 2019

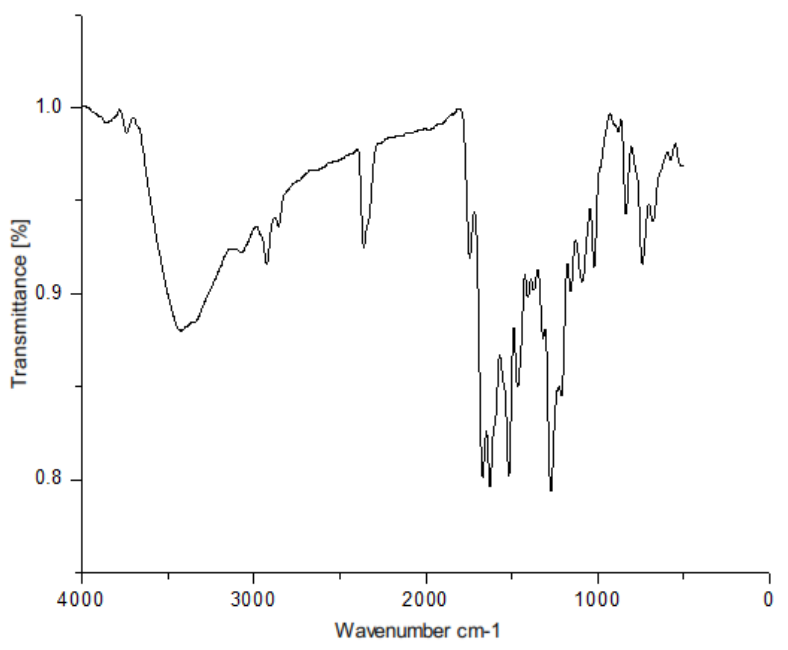

Fig.-1: FTIR Spectrum of PDAB
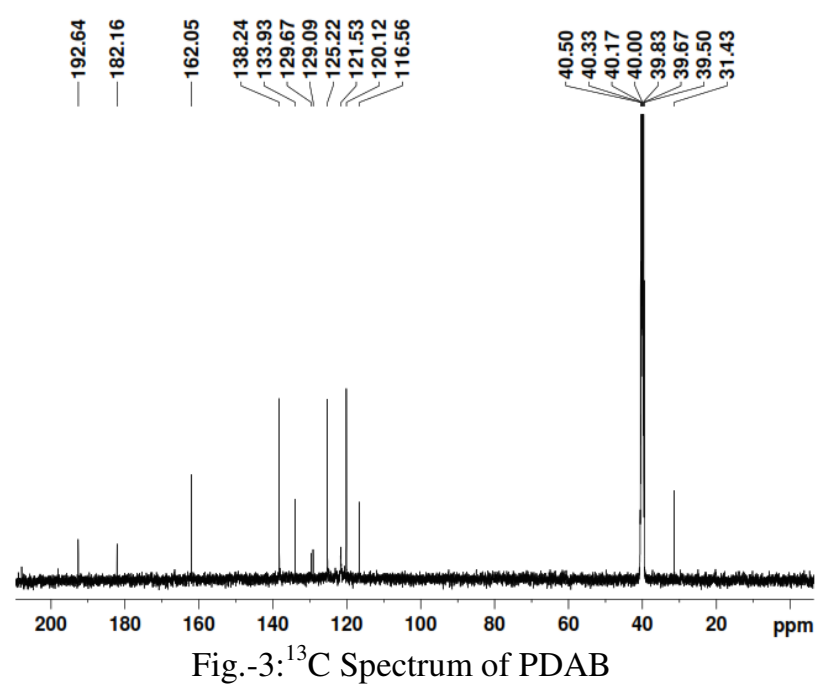

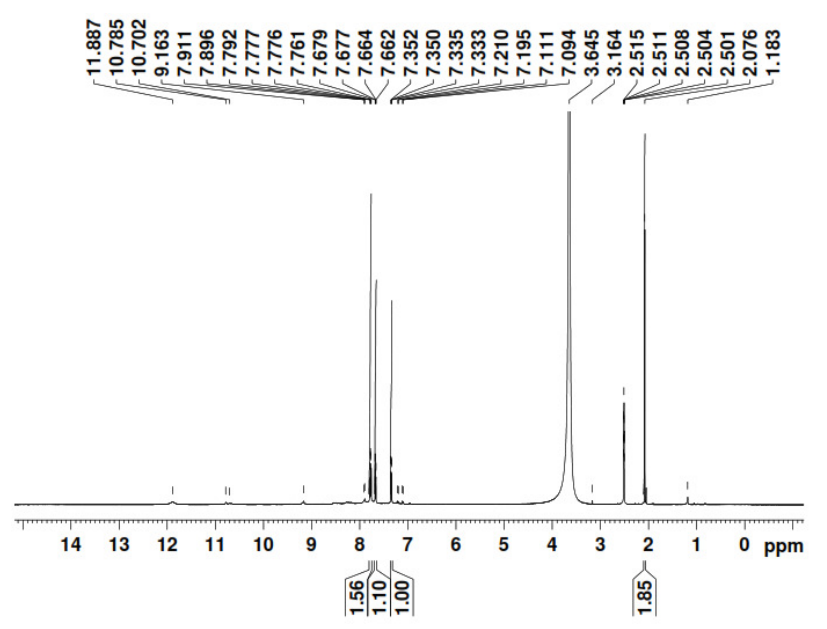

Fig.-2: ${ }^{1} \mathrm{H}$ NMR Spectrum of PDAB

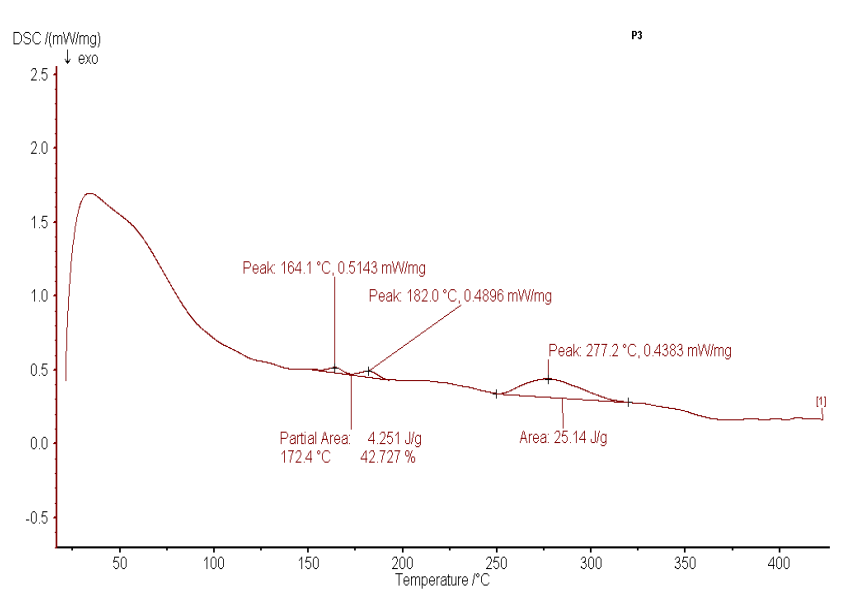

Fig.-4: DSC Thermogram of PDAB

\section{Thermal Analysis}

The phase transition temperatures of PEAs were examined accurately by differential scanning calorimetry (DSC) in a nitrogen atmosphere at the scan rate of $10^{\circ} \mathrm{C} / \mathrm{min}$. A typical DSC thermogram of PDAB for the first heating is shown in Fig.-4. From the different crystalline polymorphs, the glass transition $\left(\mathrm{T}_{\mathrm{g}}\right)$ was indicated by the peak at $164.1^{0} \mathrm{C}$. The peak at $277.2^{0} \mathrm{C}$ is due to the melting transition $\left(\mathrm{T}_{\mathrm{m}}\right)$. The peak appearing at $182.0^{\circ} \mathrm{C}$ temperature prior to melting indicates crystal to crystal transition $\left(\mathrm{T}_{\mathrm{k}-\mathrm{k}}\right)$. A similar DSC thermogram was obtained for the polymer PDAH. It is interesting to note that these two polymers were crystalline in nature. The polymers PDEH and PDEB having ether linkage in the backbone chain may exhibit less degree of crystallinity. However the polymers PDHH and PDHB were showed only one inflection point corresponding to the glass transition temperature which indicates the presence of the amorphous phase.

\section{Optical Polarizing Microscopy(OPM)}

An optical polarizing microscopy is an important tool for studying the liquid crystallinity of PEAs. The synthesized PEAs were observed by OPM and found that there is some degree of crystallinity. High rigidity of the backbones of rod-like polymers results in strong chain interaction, low solubility, high crystallinity and high melting temperatures. ${ }^{26}$ The type of mesophase is dependent on the chemical structure in the polymer backbone which contributes Physico-chemical behavior of liquid crystalline polymers. The introduction of amide linkages causing nematic liquid crystalline properties into the polyester backbone which increases the polymer chain alignment. Interestingly all the synthesized PEAs 
RASĀYAN J. Chem.

Vol. 12 | No. 4 |2124 - 2131| October - December | 2019

exhibited grainy and schlieren texture in nematic mesophase in the temperatures between $138^{\circ} \mathrm{C}-300^{\circ} \mathrm{C}$. PEAs containing anthraquinone moiety were found to be crystalline. Some of the PEAs namely PDEH and PDEB show crystal to crystal transition above $200^{\circ} \mathrm{C}$. Certain poly(ester amides) namely PDHH and PDHB also show crystal to crystal transition above $300^{\circ} \mathrm{C}$. Due to the high melting point of poly(ester amides) synthesized from 2,5-pyridinedicarboxylicacid, it was less probable to find their liquid crystalline behavior. Figure-5 presents OPM micrographs (magnification X 10) of PEAs.

(a)

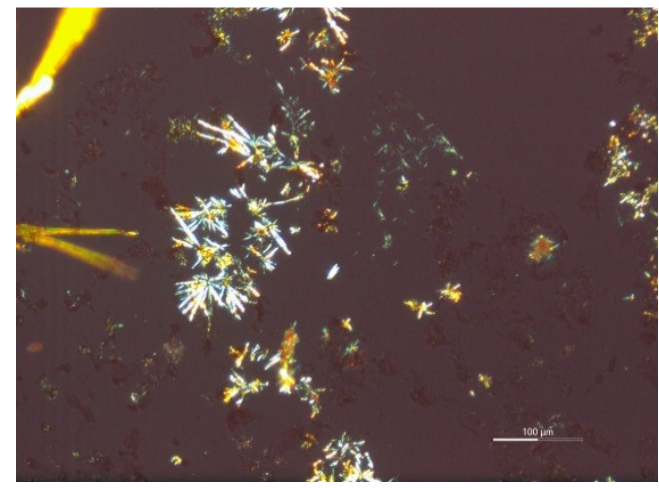

(c)

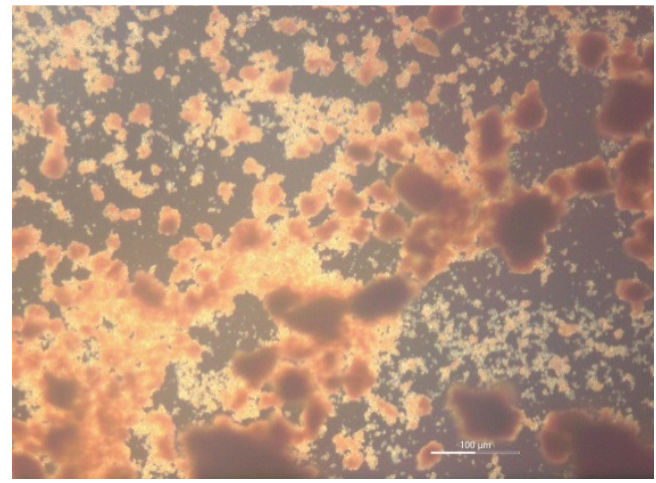

(e)

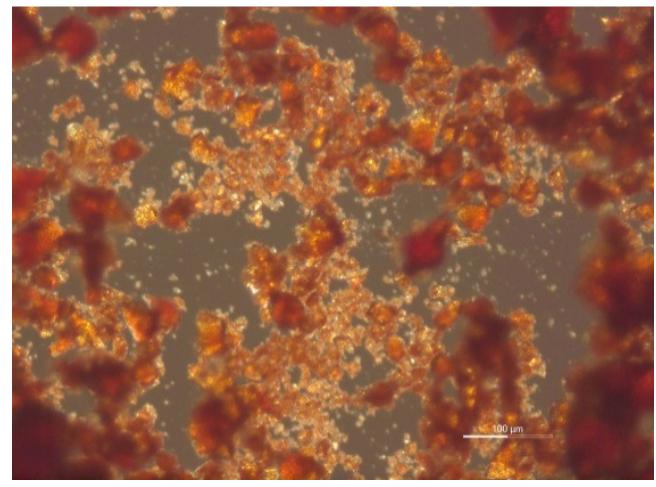

(b)

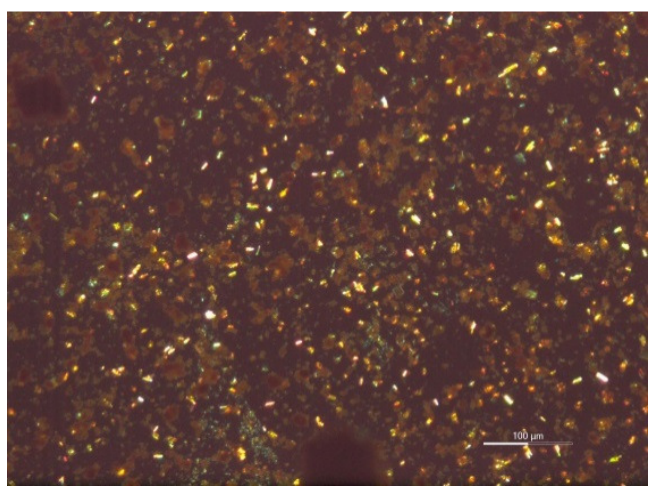

(d)

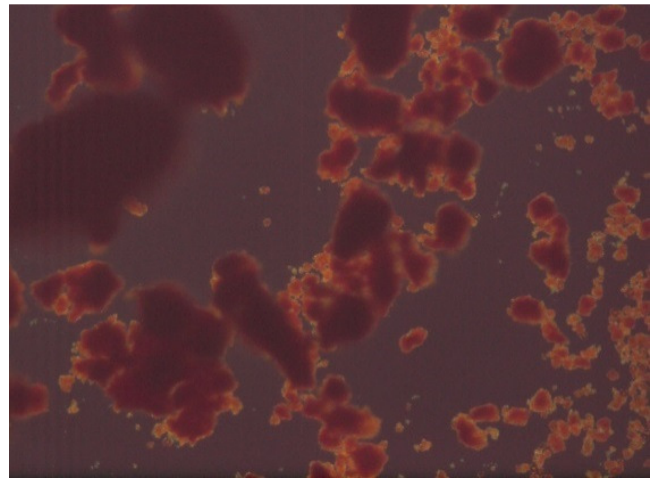

(f)

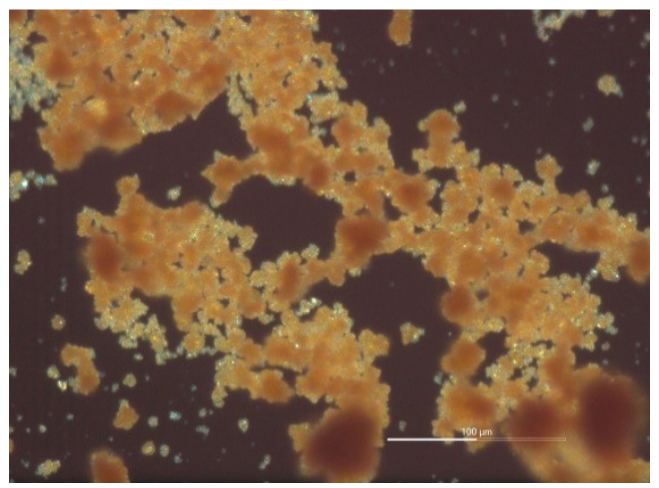

Fig.-5: Optical Polarized Micrographs of (a) PDAH at $30^{\circ} \mathrm{C}$ on Cooling (b) PDAB at $138^{\circ} \mathrm{C}$ (c) PDEH at $230^{\circ} \mathrm{C}$ (d) PDEB at $166^{\circ} \mathrm{C}$ (e) $\mathrm{PDHH}$ at $260^{\circ} \mathrm{C}$ (f) $\mathrm{PDHB}$ at $300^{\circ} \mathrm{C}$ on Heating

\section{Wide-angle X-Ray Diffraction Study (WAXD)}

The wide-angle X-ray diffraction analysis of the PEAs was conducted at room temperature to evaluate their crystal behavior. Typical X-ray diffraction patterns of PDAH and PDHH are presented in Fig.-6. It is clearly observed from the XRD pattern of PDAH show sharp and defined peaks in the region $2 \theta=5-55^{\circ}$ indicate that this polymer has a high degree of crystallinity. However, PDHH shows broad and diffuse peaks indicate that there is less degree of crystallinity in this polymer.

\section{In vitro Scratch Wound Healing Assay}

PEAs are one of the most extensively studied materials for biomedical applications. In our previous 


\section{RASĀYAN J. Chem.}

Vol. 12 | No. 4 |2124 - 2131| October - December | 2019

paper, we have reported anti-bacterial and anti-cancer properties of certain PEAs containing 2,5-pyridine dicarboxylic acid. ${ }^{27}$ Here we report wound healing property of synthesized PEAs PDEH and PDHH against vero cell lines. PDHH which contains hydroquinone is found to linearly increase in wound healing activity with an increase of concentration. This indicates that PDHH could be a potential polymer for wound healing.

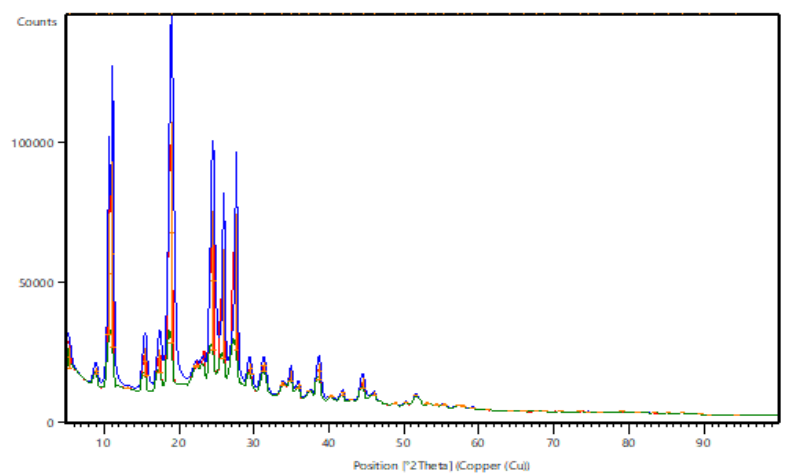

Fig. -6: WAXD Pattern of PDAH

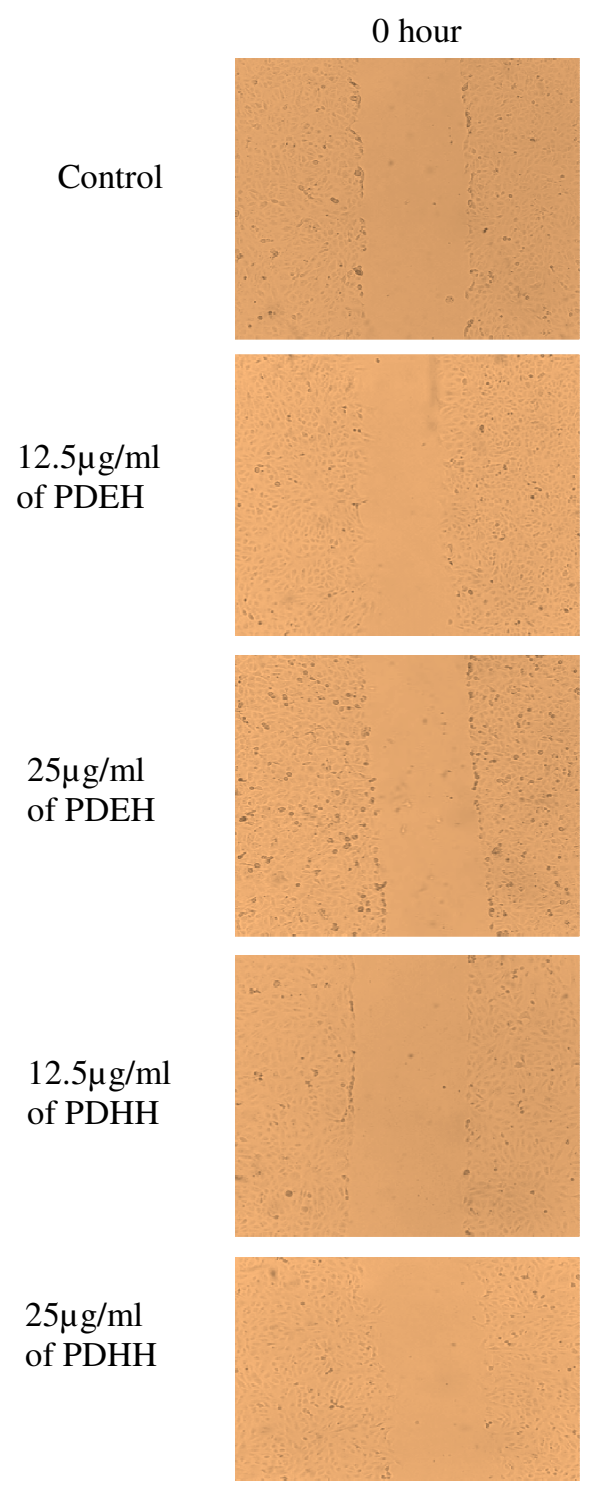



Fig. -7: WAXD Pattern of PDHH
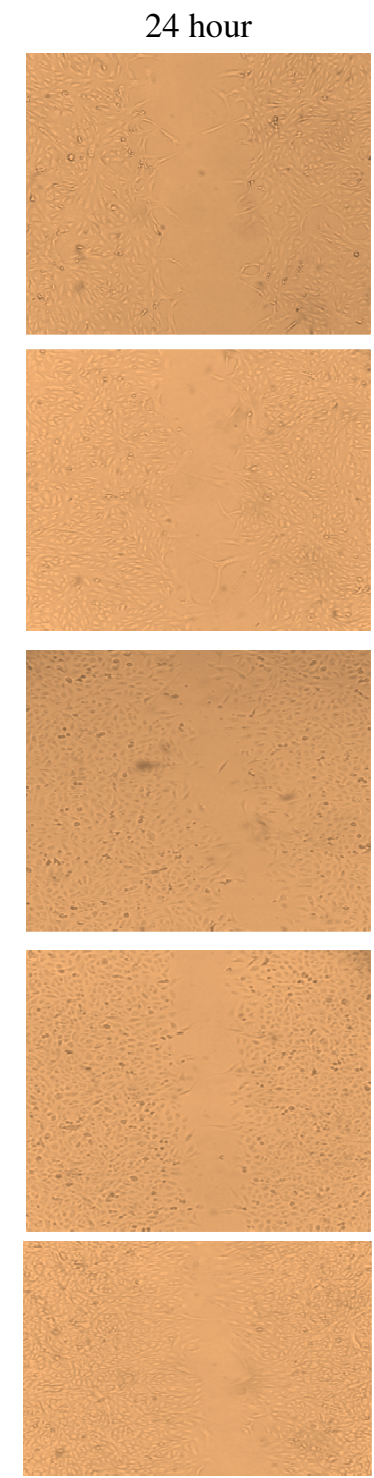

Fig.-8: In vitro Wound Scratch Assay for PDEH and PDHH 
RASĀYAN J. Chem.

Vol. 12 | No. 4 |2124 - 2131| October - December | 2019

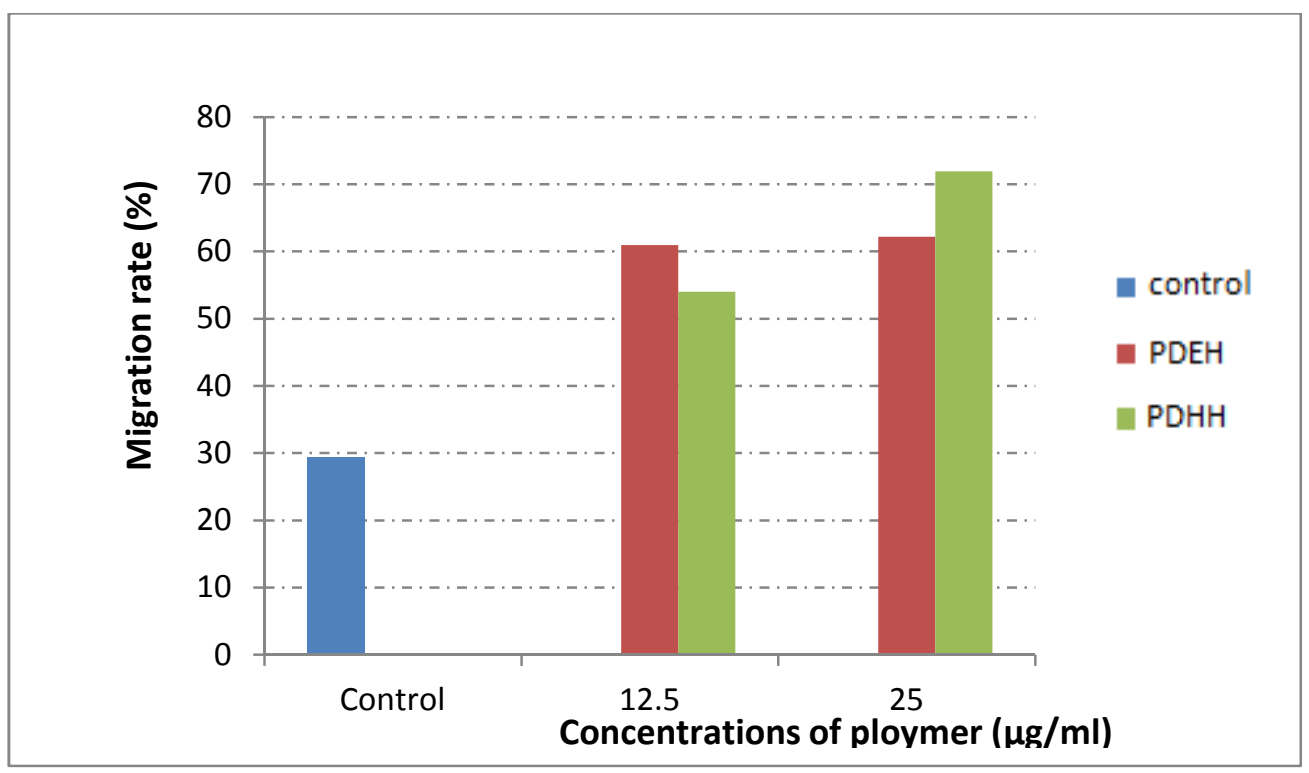

Fig.-9: Effect of PEAs on Cell Viability

Six novel PEAs were synthesized from 2,5-pyridine dicarboxylic acid, two different diols, and diamines by direct polycondensation using DPPC as the condensation agent in pyridine medium in the presence of $\mathrm{LiCl}$. PEAs synthesized were in high yield and inherent viscosities range between 1.09 and $1.27 \mathrm{dL} / \mathrm{g}$. The microstructures of the polymers have been investigated by ${ }^{1} \mathrm{H},{ }^{13} \mathrm{C}-\mathrm{NMR}$ and FTIR spectra. The thermal behavior of this new class of PEAs was studied by DSC. Data revealed that these polymers showed good thermal stability. There is an extensive application for PEAs, since they combine the mechanical properties of polyamides with the degradability of polyesters. Optical polarizing microscopy was used to establish the mesophase formation and all the polymers were found to be schlieren and grainy texture indicating nematic mesophase. Polymer textures were observed by OPM supports the phase transition temperatures observed by DSC analysis. From the WAXD patterns of the PEAs they were predominantly found to be semi-crystalline in nature. One of the PEAs namely PDHH tested for wound healing property which showed significant activity. The PEAs synthesized could be potentially utilized in various biomedical fields including antibiotics and biosensors.

\section{REFERENCES}

1. K. Ghosal, M. S. Latha and S. Thomas, European Polymer Journal, 60, 58 (2014), DOI:10.1016/j.eurpolymj.2014.08.006

2. S. K. Murase, and J. Puiggali, 2014, Natural and Synthetic Biomedical Polymers, pp.145-166.

3. G. Jokhadze, M. Machaidz, H. Panosyan, C. C. Chu and R. Katsarava, Journal of Biomaterials Science, Polymer Edition, 18(4), 411 (2007), DOI:10.1163/156856207780425031

4. A. R. Galan, L. Franco and J. Puiggali, Polymers,3, 65 (2011), DOI:10.3390/polym3010065

5. U. Edlund and A. C.Albertsson, Advanced Drug Delivery Reviews, 55(4), 585(2003), DOI: 10.1016/S0169-409X(03)00036-X

6. P. A. M. Lips, R. Broos, M. J. M. venHeeringen, P. J. Dijkstra and J. Feijen, Polymer,46(19), 7823 (2005), DOI:10.1016/j.polymer.2005.07.013

7. A. D. Matthew, W. Zixi, M. A. Katelyn, M. Kibret and R. G. Elizabeth, Journal of Polymer Science Part A: Polymer Chemistry, 46(19), 6376 (2008), DOI:10.1002/pola.22915

8. L. S. Nair and C. T. Laurencin, Progress in Polymer Science,32, 762(2007), DOI:10.1016/j.progpolymsci.2007.05.017

9. J. D. Sudha and C. K. S. Pillai, Journal of Polymer Science Part A: Polymer Chemistry,41(2), 335 (2003), DOI:10.1002/pola.10576

10. A. Soleimani, S. Drappel, R. Carlini, A. Goredema and E. R.Gillies, Industrial \& Engineering Chemistry Research, 53(4), 1452 (2014), DOI:10.1021/ie4035219 
RASĀYAN J. Chem.

Vol. 12 | No. 4 |2124 - 2131| October - December | 2019

11. P. Garg, H. Keul, D. Klee and M.Moller, Macromolecular Chemistry and Physics,210(20), 1754 (2009), DOI:10.1002/macp.200900232

12. S. M. Ataei, M. H. Mosslemin, S. Kholghi and S. M. Mohaghegh, e-Polymer,43, 1(2009),

13. A. Abdolmaleki, S. Mallakpour and S. Borandeh, Polymer Bulletin, 69(1), 15(2012), DOI: 10.1007/s00289-011-0685-7

14. V. A. E. Shaikh, V. P. Ubale, N. N. Maldar, S.V. Lonikar, C. R. Rajan and S. Ponrathnam, Journal of Applied Polymer Science, 100, 73 (2006), DOI: 10.1002/app.22286

15. D. Mingxiao, W. Jun, A. Cynthia, Reinhart-King and C. C. Chu, Biomacromolecules., 10(11), 3037 (2009), DOI: $10.1021 / \mathrm{bm} 9006437$

16. M. A. Katelyn, L. David, K. K. Darryl, M. KibretR. Katsarava and R. G. J. Elizabeth, Journal of Biomaterials Science, Polymer Edition, 18, 411 (2009).

17. B. D. Ulery,L. S. Nair and C. T. Laurencin, Journal of Polymer Science Part B: Polymer Physics, 49, 832 (2011), DOI:10.1002/polb.22259

18. P. E. Naidu, E. Arumugasamy, E. Ravichandran, V. Kannappan and I. K.Varma, Molecular Crystals and Liquid Crystals Science and Technology. Section A. Molecular Crystals and Liquid Crystals, 287, 1 (1996), DOI:10.1080/10587259608038738

19. A. Douka, S. Vouyiouka, L. -M. Papaspyridi and D. P. Constantine, Journal of Applied Polymer Science,79, 1 (2018), DOI:10.1016/j.progpolymsci.2017.10.001

20. V. Kannapan and D. Reuben Jonathan, Journal of Chemical and Pharmaceutical Research,5(4) 382 (2013).

21. M. Mayavathi, V. Chitra, P. Sathish and D. Roopsingh, International Journal of ChemTech Research, 7, 2956 (2015).

22. K. Muniandy, S. Gothai, W. Sean Tan, S. Suresh Kumar, N. MohdEsa, G. Chandramohan, K.S. AlNumair and P. Arulselvan, Evidence Based Complementary and Alternative Medicine1(2018), DOI: $10.1155 / 2018 / 3142073$

23. G. C. East and V. G. R. Gudiguntla Macromolecular Chemistry and Physics, 195, 1851, (1994), DOI:10.1002/macp.1994.021950532

24. L. Wasylina, E. Kucharska, Z. Weglinski and A. Puszko, Chemistry of Heterocyclic Compounds, 35, 186 (1999), DOI:10.1007/BF02251707

25. MisbahUlHasan Organic Magnetic Resonance, 14, 447 (1980), DOI:10.1002/mrc.1270140605

26. D. K. Deak, R.W. Lenz and S.W. Kantor, Journal of Polymer Science Part A: Polymer Chemistry, 35, 197 (1997), DOI:10.1002/(SICI)1099-0518(19970130)35:2<197::AID-POLA1>3.0.CO;2-Q

27. V. Chitra and D. Roopsingh, Journal of Drug Delivery and Therapeutics. 8, 166 (2018), DOI: 10.22270/jddt.v8i6-s.2107

[RJC-5431/2019] 